\title{
Health Care Efficiency In Transition Economies: An Application Of Data Envelopment Analysis
}

Sam Mirmirani, (Email: smirmira@bryant.edu), Bryant University

H.C. Li, Bryant University

Joseph A. Ilacqua, Bryant University

\begin{abstract}
Health care costs are a financial burden for developing and transition economies which have experienced a faster growing demand on their health care systems while aiming to improve efficiency. As costs become more complex, attention has shifted to the efficiency of an entire system. Through system-wide assessments, countries with higher health care efficiency can be identified. These systems can be replicated to allow provision of good care at lower costs. Data Envelopment Analysis is used to measure health care efficiencies and to discuss policy implications.
\end{abstract}

Key terms: Health Care Efficiency, Transition Economies, Data Envelopment Analysis, Health Policy

\section{INTRODUCTION}

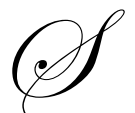

teady increase in health care costs has been a financial burden to many economies for a number of years. This problem is of particular concern to developing and transition economies, where other vital services, such as social security and re-industrialization are also competing for public funds. In 2001, the transition economies investigated in this study had a mean per-capita health care expenditure of about $\$ 130.5$, an increase of $16.5 \%$ from that of 1997. The OECD nations averaged about $\$ 1,786$ in 2001, which represents a $7.2 \%$ increase since 1997, OECD (2004). These figures suggest that transition economies experienced a faster growing demand than their Western counterparts for the provisioning of adequate health care to their citizens. To contain health care costs, both industrial and transition economies are aiming to improve the efficiency of their health care systems.

The majority of research in the area of health care efficiency has focused on the firm/organizational level. For example, see Braithwaite, et. at. (2006) and Brennan et. al. (2005) on hospitals; Key et. al. (2005) on pharmaceutical industry; Brockett et. al. (2004) on Health Maintenance Organizations (HMO) industry; and Bjorkgren et. al. (2001) on long term care. However, as the containment of health care costs becomes more difficult, the focus of attention has been shifted to the efficiency of an entire health care system. Through systemwide assessments, countries with higher healthcare efficiency can be identified. Borrowing from the experience of efficient systems, a country is better able to provide more adequate health care at lower costs to its citizens.

Among the various methods of efficiency assessment, Data Envelopment Analysis (DEA) has gained the attention of many researchers (Cooper, Seiford, and Tone, 2000). Although there are published system-wide comparisons of health care efficiency, we have not identified any research which applies the DEA method in assessing macro-level efficiencies.

In this paper the DEA technique is used to measure health care efficiencies of transition economies and to discuss potential policy implications of the findings. The organization of the paper is as follows: First, a review of literature is provided. Next, the DEA methodology is elaborated upon. This is followed by empirical testing and analysis. Summary and conclusions are given in the last section. 


\section{LITERATURE REVIEW}

With a focus on health care systems of OECD countries, Anell and Willis (2000) suggest that, instead of expenditure measures, using resource profiles is a more desirable alternative for making international comparisons. In another OECD-based study, Anderson, et al. (2003) suggest that differences in health care spending patterns between the United States and the rest of the member countries are mostly explained by higher costs in the US. Thus, the use of real variables would make an international comparison more meaningful. Evans, et al. (2001) applied a regression technique to assess relative efficiencies of national health care systems of 191 countries. Using life expectancy as the-output and health expenditures and average schooling as inputs, they conclude that, while the use of additional resources results in an improvement in public health, a more efficient use of resources can also contribute to the delivery of better health care in a system.

Although most Data Envelopment Analysis studies focus on corporate efficiency, there are a few papers which examine system-wide efficiency at macro-level. For example, Dimelis and Dimopoulou (2002) use DEA to evaluate the productivity growth of countries in the European Union. They suggest that because DEA does not impose any constraints on production functions, it frees the user from assigning a priori assumptions on production technology and economies of scale. In another study, Cherchye (2001) uses DEA to assess macroeconomic policy performance of OECD countries. The use of DEA allows the ranking of policy impacts in the observed countries without defining the transmission mechanism of individual policies.

In health care research, the use of DEA has gained much popularity in the 1990's. Hollingsworth, et al. (1999) provide a thorough review of various applications at the micro level. More recent applications of DEA to measure hospital efficiency can be found in Bhat (2001), Giokas (2002), and Hofmarcher, et al. (2002). These studies elaborate on DEA's applicability, strengths and limitations. Methodological comparisons between DEA and regression analysis have been discussed by Nyhan and Cruise (2000), who examined the efficiency of managed care organizations; and by Giuffrida and Gravelle (2001), who investigated the delivery of primary care. Seiford (1996) Berger, et al. (1997), and Cooper, et al. (2000) point out that DEA has the following advantages over regression analysis: (1) unlike linear or non-linear regression, DEA does not require any pre-specified functional form between inputs and outputs; (2) while a regress function reveals the "average" efficiency of the units under investigation, DEA shows their efficient frontier; (3) when multiple outputs and inputs are used in a study, contrary to regress techniques, DEA does not require the construction of any subjective efficiency index to identify the most efficient production units. Additionally, Smith (1997) suggests that DEA's ability to provide meaningful results with a small sample also contributes to its growing popularity. Despite these mythological advantages, no statistical inference can be associated with the DEA efficient frontier because it is not derived from statistical analysis but from mathematical programming.

\section{THE DEA MODEL}

Using mathematical programming, DEA estimates the optimal combinations of inputs and outputs, or the efficiency frontier. It allows a researcher to reveal the technical efficiency of each production unit (also known as a decision-making unit (DMU)). DEA gives an estimate of the extent of inefficiency of a given DMU, relative to the best performing DMU. A DMU is considered technically inefficient if it lies below the efficient frontier. DMUs on the frontier are, of course, the efficient units.

The theoretical framework of DEA was first introduced in a seminal study by Charnes, Cooper, and Rhodes (1978). This framework is known as the CCR model. Their study extended the single-output-input technical efficiency measure, pioneered by Farrell (1957), to a multiple output-input relative efficiency measure. Since then, a number of variations and extensions of the original model as well as related software have been introduced. See, for example, Cooper, et al. (2000) and Thanassoulis (2001).

Two fundamental versions of the CCR model have been introduced. One is input-oriented, while the other is output-oriented. The objective of the input-oriented CCR model is to minimize inputs for producing given levels 
of outputs. The purpose of the output-oriented CCR model is to maximize outputs by using no more than given amounts of inputs.

First, consider the input-oriented CCR model. Assume that there are $s$ health care systems (DMUs), each with a set of $j$ outputs $\left(y_{i r}, i=1,2, \cdots, j, r=1,2, \cdots, s\right)$ and a set of $l$ inputs $\left(x_{k r}, k=1,2, \cdots, l, r=1,2, \cdots, s\right)$. The efficiency parameter $\left(\theta_{r}\right)$ of the $r$ th DMU is determined by solving the following fractional programming problem to obtain the output weights $u_{i}(i=1,2, \cdots, j)$ and the input weights $v_{k}(k=1,2, \cdots, l)$.

$$
\begin{aligned}
& \text { Maximize } \quad \theta_{r}=\underset{i=1}{\left(\sum_{i=1}^{j} u_{i} y_{i r}\right) /\left(\sum v_{k} x_{k r}\right),}, \\
& \text { subject to } \quad \theta_{r} \leq 1, r=1, \cdots, s \text {, } \\
& u_{i} \geq 0, i=1,2, \cdots, j \text {, and } \\
& v_{k} \geq 0, k=1,2, \cdots, l \text {. }
\end{aligned}
$$

Following Cooper, et al. (2000), this fractional programming problem is equivalent to the following linear programming problem:

$$
\begin{aligned}
& \operatorname{maximize} \quad \theta_{r}=\underset{\sum}{\substack{i=1 \\
i=1}} u_{i} y_{i r} \\
& l \\
& \text { subject to } \quad \sum v_{k} x_{k r}=1 \text {, } \\
& k=1
\end{aligned}
$$

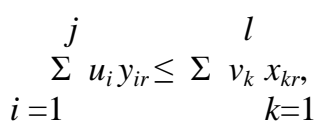

$$
\begin{aligned}
& u_{i} \geq 0, i=1,2, \cdots, j \text {, and } \\
& v_{k} \geq 0, k=1,2, \cdots, l \text {. }
\end{aligned}
$$

The input-oriented CCR model, as delineated above, poses no additional constraints. It determines input weights and output weights, which in turn determine the efficiency parameter $(\theta)$ of each DMU. An investigator, who evaluates the efficiency of health care systems, is not required to make any subjective assignment of these weights. A health care system with an efficiency parameter of " 1 " is said to be efficient and on the efficient frontier; otherwise, inefficient and below the frontier. The extent of inefficiency of a DMU is measured by the deviation of its efficiency parameter value from 1.

The efficiency derived from the CCR model requires that $\theta=1$ and that there is no input slack. This CCR efficiency is equivalent to the Pareto-Koopmans efficiency, which is often cited in economic literature. The efficiency cited by Farrell (1957) requires only $\theta=1$ without satisfying the condition of zero input slack (Cooper, et al. 2000).

Using matrix notations, the above linear programming problem can be restated as: 


$$
\begin{array}{ll}
\operatorname{maximize} & \theta_{r}= \\
\text { subject to } & \boldsymbol{u} \boldsymbol{y}_{r}, \\
& \boldsymbol{v} \boldsymbol{x}_{r}=\mathbf{1}, \\
& -\boldsymbol{v} \boldsymbol{X}+\boldsymbol{u} \boldsymbol{Y} \leq \mathbf{0}, \\
& \boldsymbol{u} \geq \mathbf{0}, \text { and } \\
& \boldsymbol{v} \geq \mathbf{0}, \\
& \boldsymbol{u}=u_{i}, i=1,2, \cdots, j, \\
& \boldsymbol{v}=v_{k}, k=1,2, \cdots, l, \\
& \boldsymbol{x}_{r}=x_{k r}, k=1,2, \cdots, l \text { for the } r \text { th DMU, } \\
& \boldsymbol{y}_{r}=y_{i r}, i=1,2, \cdots, j \text { for the } r \text { th DMU, } \\
& \boldsymbol{X}=x_{k}, k=1,2, \cdots, l, r=1, \cdots, s, \text { and } \\
& \boldsymbol{Y}=y_{i r}, i=1,2, \cdots, j, r=1, \cdots, s .
\end{array}
$$

The dual problem of the above model becomes

minimize $\quad \theta_{r}$

subject to

$$
\begin{aligned}
& \theta_{r} \boldsymbol{x}_{r}-\boldsymbol{X} \boldsymbol{\lambda} \geq \mathbf{0}, \\
& \boldsymbol{Y} \boldsymbol{\lambda} \geq \boldsymbol{y}_{r}, \text { and } \\
& \lambda \geq \mathbf{0},
\end{aligned}
$$

where $\theta_{r}$ is a real variable, and $\lambda=\left(\lambda_{1}, \cdots, \lambda_{s}\right)$ is a non-negative vector.

Following Cooper, et al. (2000), define $\eta_{r}=1 / \theta_{r}$ and $\boldsymbol{\mu}=\eta_{r} \lambda$, the input-oriented CCR model can be converted into the output-oriented CCR model. That is,

$$
\begin{array}{cl}
\operatorname{maximize}: & \eta_{r} \\
\text { subject to } & \boldsymbol{x}_{r}-\boldsymbol{X} \boldsymbol{\mu} \geq \mathbf{0}, \\
& \eta \boldsymbol{y}_{r}-\boldsymbol{Y} \boldsymbol{\mu} \leq \mathbf{0}, \\
& \boldsymbol{\mu} \geq \mathbf{0} .
\end{array}
$$

$\eta_{r}$ is expected to be greater or equal to 1.

Thus, mathematically, the input-oriented CCR model is equivalent to its output-oriented counterpart. If the policy emphasis of health care systems is to minimize inputs for producing given levels of outputs, the use of inputoriented CCR is more appropriate for efficiency evaluation. On the other hand, if policy makers place more emphasis on the maximization of outputs by using given amounts of inputs, the employment of an output-oriented model for efficiency evaluation becomes more suitable. Whatever the selection, when the $\theta$ value of a health care system reaches 1, the DMU has obtained the Pareto-Koopmans efficiency.

\section{EMPIRICAL TESTING AND ANALYSIS}

After the collapse of the Soviet Union, the newly independent states (NIS) and the Eastern European countries experienced economic chaos and instability. Although efforts were made by these countries to privatize manufacturing and commercial sectors to raise productivity, it was not the priority of these governments to drastically reduce inputs to the health care sector for improving efficiency. Also, the majority of health care workers 
are highly trained and over the years, a significant amount of investments have been made by the governments. It is expected that any structural change in the political and economic systems may have so called "brain drain" consequences. This effect can be more pronounced and bear further economic losses to the nation if the government attempts to reduce the size of health care inputs as a means of efficiency improvement. Thus, it seems more appropriate to use the output-oriented CCR model to evaluate the efficiency of health care systems of these countries.

There are two main factors in determining the choices of variables used in this study: consistency of measurement among transition economies and the availability of data. The period of investigation is 1997-2001. The majority of the data is extracted from World Development Indicators, UNICEF, and World Bank databases.

Output variables are the average (male and female) life expectancy and infant mortality rates. As evidenced by most of the previous health care related studies, these are two commonly reported national health care outcomes. For inputs, it is our intention to include variables, which are proxies for financial as well as physical factors that influence health care outcomes in these countries. These inputs are: per capita health care expenditure in U. S. dollars after adjustment for purchasing power parity, number of inpatient hospital beds per thousand population, number of physicians per thousand population, and immunizations. Although there are many ways to measure "immunization," limited by the availability of data, we use the percentage of children with measles inoculation as its proxy.

\begin{tabular}{|c|c|c|c|c|c|c|c|c|c|c|}
\hline \multicolumn{11}{|c|}{ Table 1: Country-Specific Health Care Statistics, 1997-2001 } \\
\hline Year & Variables & Alba & Arme & Bela & Esto & Latv & Lith & Roma & Russ & OECD \\
\hline \multirow{6}{*}{1997} & Life Exp. & 72 & 74 & 68 & 70 & 70 & 71 & 69 & 67 & 76 \\
\hline & Inf. Mortality/1000 & 34 & 25 & 14 & 13 & 16 & 13 & 22 & 20 & 8 \\
\hline & Physician/1000 & 1 & 3 & 4 & 3 & 3 & 4 & 2 & 4 & 3 \\
\hline & Beds/1000 & 3 & 7 & 12 & 8 & 10 & 10 & 7 & 11 & 4 \\
\hline & Measles & 95 & 92 & 97 & 88 & 97 & 96 & 97 & 91 & 90 \\
\hline & Health Exp/capita & 28 & 36 & 82 & 182 & 157 & 165 & 79 & 167 & 1658 \\
\hline \multirow{6}{*}{1998} & Life Exp. & 73 & 74 & 68 & 70 & 70 & 72 & 69 & 67 & 77 \\
\hline & Inf. Mortality & 30 & 25 & 22 & 18 & 18 & 19 & 21 & 21 & 7 \\
\hline & Physician/1000 & 1 & 3 & 4 & 3 & 3 & 4 & 2 & 4 & 3 \\
\hline & Beds $/ 1000$ & 3 & 7 & 12 & 8 & 9 & 10 & 7 & 11 & 4 \\
\hline & Measles & 89 & 94 & 98 & 89 & 97 & 97 & 97 & 94 & 89 \\
\hline & Health Exp/capita & 34 & 42 & 67 & 223 & 171 & 197 & 124 & 112 & 1690 \\
\hline \multirow{6}{*}{1999} & Life Exp. & 74 & 73 & 68 & 71 & 70 & 72 & 70 & 66 & 77 \\
\hline & Inf. Mortality & 29 & 25 & 23 & 17 & 17 & 18 & 21 & 18 & 7 \\
\hline & Physician/1000 & 1 & 3 & 5 & 3 & 3 & 4 & 2 & 4 & 3 \\
\hline & Beds/1000 & 3 & 6 & 13 & 8 & 9 & 10 & 7 & 11 & 4 \\
\hline & Measles & 85 & 92 & 98 & 92 & 97 & 97 & 98 & 97 & 90 \\
\hline & Health Exp/capita & 43 & 46 & 63 & 244 & 190 & 190 & 108 & 71 & 1763 \\
\hline \multirow{6}{*}{2000} & Life Exp. & 74 & 74 & 68 & 71 & 70 & 73 & 70 & 65 & 77 \\
\hline & Inf. Mortality & 24 & 25 & 17 & 11 & 17 & 17 & 19 & 18 & 7 \\
\hline & Physician/1000 & 1 & 3 & 5 & 3 & 3 & 4 & 2 & 4 & 4 \\
\hline & Beds/1000 & 3 & 5 & 13 & 7 & 9 & 10 & 7 & 11 & 4 \\
\hline & Measles & 95 & 92 & 98 & 93 & 97 & 97 & 98 & 97 & 90 \\
\hline & Health Exp/capita & 46 & 49 & 56 & 222 & 191 & 200 & 109 & 95 & 1680 \\
\hline \multirow{6}{*}{2001} & Life Exp. & 73 & 73 & 69 & 71 & 71 & 72 & 70 & 66 & 78 \\
\hline & Inf. Mortality & 26 & 31 & 17 & 11 & 17 & 8 & 19 & 18 & 7 \\
\hline & Physician/1000 & 1 & 3 & 5 & 3 & 3 & 4 & 2 & 4 & 3 \\
\hline & Beds/1000 & 3 & 4 & 13 & 7 & 8 & 9 & 7 & 11 & 4 \\
\hline & Measles & 95 & 93 & 99 & 95 & 98 & 97 & 98 & 97 & 90 \\
\hline & Health Exp/capita & 48 & 54 & 68 & 226 & 210 & 206 & 117 & 115 & 1786 \\
\hline
\end{tabular}

Sources: Life expectancy: http://www.worldbank.org/depweb/english/modules/social/life/dataeuro.html; Infant Mortality: http://www.unicef.org/sowc00/; Others: World Development Indicators, World Bank 
Table 1 shows the inputs and outputs of Albania, Armenia, Belarus, Estonia, Latvia, Lithuania, Romania, and Russia from 1997 to 2001. To compare the efficiency of health care systems of transition economies with that of Western countries, Table 1 also provides the comparable OCED data over the same period of time.

Using the output-oriented CCR model, each DMU's efficiency is measured and ranked. The efficiency ranking of OCED and that of each transition country are given in Table 2. A DMU with a rank of " 1 " suggests that it has an efficiency score of 1, and is on the efficient frontier. An efficiency score of less than one suggests that the DMU is less efficient, and lies below the efficient frontier. The lower the score the lower the efficiency.

\begin{tabular}{|c|c|c|c|c|c|c|c|c|c|c|c|c|c|c|}
\hline \multicolumn{15}{|c|}{ Table 2: Efficiency measures and ranks } \\
\hline \multicolumn{3}{|c|}{1997} & \multicolumn{3}{|c|}{1998} & \multicolumn{3}{|c|}{1999} & \multicolumn{3}{|c|}{2000} & \multicolumn{3}{|c|}{2001} \\
\hline 范 & 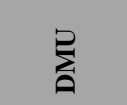 & 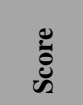 & こ & $\sum^{\varrho}$ & 苞 & $\begin{array}{l}\text { E् } \\
\text { Е }\end{array}$ & $\sum^{\varrho}$ & हैं & 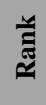 & 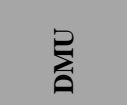 & 苞 & 芩 & 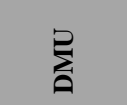 & ֻّ \\
\hline 1 & Albania & 1 & 1 & Albania & 1 & 1 & Albania & 1 & 1 & Albania & 1 & 1 & Albania & 1 \\
\hline 1 & Armenia & 1 & 1 & OECD & 1 & 2 & OECD & 0.983 & 1 & Armenia & 1 & 1 & Armenia & 1 \\
\hline 1 & Belarus & 1 & 3 & Armenia & 0.960 & 3 & Armenia & 0.922 & 1 & OECD & 1 & 1 & OECD & 1 \\
\hline 1 & Estonia & 1 & 4 & Estonia & 0.953 & 4 & Estonia & 0.886 & 4 & Estonia & 0.944 & 4 & Estonia & 0.943 \\
\hline 1 & OECD & 1 & 5 & Lithuania & 0.901 & 5 & Lithuania & 0.853 & 5 & Lithuania & 0.931 & 5 & Lithuania & 0.938 \\
\hline 6 & Lithuania & 0.961 & 6 & Latvia & 0.876 & 6 & Latvia & 0.829 & 6 & Romania & 0.902 & 6 & Romania & 0.917 \\
\hline 7 & Romania & 0.931 & 7 & Russia & 0.867 & 7 & Romania & 0.820 & 7 & Latvia & 0.895 & 7 & Latvia & 0.917 \\
\hline 8 & Russia & 0.915 & 8 & Romania & 0.865 & 8 & Belarus & 0.797 & 8 & Belarus & 0.863 & 8 & Belarus & 0.887 \\
\hline 9 & Latvia & 0.909 & 9 & Belarus & 0.845 & 9 & Russia & 0.782 & 9 & Russia & 0.832 & 9 & Russia & 0.864 \\
\hline
\end{tabular}

As shown in Table 2, the ranking of DMUs under investigation can be divided into four groups. Consistently, Albania and Armenia managed to maintain their health care systems as efficiently as that of OECD countries average. The three DMUs were always followed by Estonia and Lithuania of the second group. One would expect OECD to maintain first ranking for the entire period as can be evidenced by the data. However, in 1999 they took the second rank, below Albania. This might be explained by the presence of randomness in the data which could not be corrected in the DEA model. Latvia and Romania constituted the third group. Each country in this group had a ranking varying slightly over time, but consistently below those of Estonia and Lithuania. The last group consisted of Russia and Belarus. In most years, they were ranked as the most inefficient DMUs.

With the break-up of the Soviet empire, all transition countries in this study were subject to a serious economic downturn and depletion of both financial and physical resources. In addition, many of these countries had serious issues with rampant alcohol consumption and smoking. It is interesting to contrast the socio-demographic factors of the top performers (i.e., Albania and Armenia) with those of the bottom-tier DMUs (i.e., Russia and Belarus) to gain additional insights into their health care systems.

A quick glance at Table 1 reveals that Albania had the lowest number of hospital beds, physician to population ratios, per-capita health care expenditures and a significant percent of children with measles inoculations. Surprisingly, their infant mortality remained the lowest among the transition countries included in this study, while its life expectancy outcome was, for the most part, the highest. It is worth noting that, over the period of this study, Albania's population was fairly young, roughly $40 \%$ under the age of 18 . With better nutrition, relatively lower alcohol consumption and smoking rates, Albanians were known to have a "healthier lifestyle." See, European Observatory on Health Care Systems report (2003).

With independence came resource constraints in Armenia. To sustain their health care system, the Armenian government sought assistance from abroad. The two main sources of assistance came from the United States and Canada. The USAID program focused on improvement in health care, particularly women's health and primary care delivery. A closer relationship between the U. S. health care institutions and their Armenian counterparts was an integral part of the assistance package. Canadian assistance concentrated on the exchange of health care professionals, and mutual visitations of executives of government and non-governmental health agencies. 
The Armenian government made extra efforts to reduce infectious diseases and to control epidemiological cases. To deal with a smoking problem, Armenia participated in the Global Anti-tobacco Treaty by becoming a contracting party (Stephenson, 2005).

Belarus had the highest number of hospital beds and physicians per thousand population. Its per capita health care expenditure exceeded those of Albania and Armenia. Yet, their life expectancy, only slightly better than that of Russia, was one of the lowest in the study group. The infant mortality rate, however was lower than many other transition countries. Belarus devoting $5 \%$ of its GDP to health care, noticeably higher than most other nations in the group, a level of funding that could be expected to yield better health care outcomes. According to a report by the World Bank, Belarus' inability to reduce the excessive alcohol and tobacco consumption hindered the efficiency of the it's health care system. In addition to inadequate prevention and treatment of cardiovascular disease, Belarus faced the danger of a renewed epidemic of communicable diseases such as tuberculosis, HIV/AIDS and other sexually transmitted diseases. Inefficiency in Belarus' health care system was also attributable to poor management. With an outdated budgeting and accounting system, the true cost of service cannot be determined, resulting in an improper allocation of resources amongst different service providers. Lack of an incentive mechanism exacerbated further inefficiencies. Weaknesses in primary health care delivery tend to shift patients from low cost clinical establishments to expensive hospitals for minor illnesses (World Bank 2002).

Russia, after the breakup of the Soviet Union in 1991, suffered a significant rise in its mortality rate. In addition to a high rate of alcohol and tobacco consumption, increases in psychological stress, income inequality and a decline in social and health insurance were the prime causes of poor health care outcomes. Environmental factors, as well as an increase in epidemics and infectious diseases, added to the complexity of the health care crisis in Russia. Cockerham, Snead and Dewaal, (2002) blamed socialism for constraining the positive life style in Russia.

It is worth pointing out that, methodologically, DEA is not a tool of statistical analysis. Although efforts have been made to incorporate statistical techniques into DEA models, the results are less than desirable (Cooper, Seiford and Tone, 2000). The inclusion of socio-demographic factors as random variables would not make the investigation of health care efficiency more fruitful. In addition, the issue of small sample size makes it undesirable to employ a statistical approach for ranking system wide efficiency. The DEA outcomes shown in Table 2 suggest that the rankings of these DMUs are relatively stable over time.

\section{CONCLUSION}

The break-up of the Soviet Union in 1991 resulted in dramatic changes in all of its Republics, now known as transition economies. The term "transition economies" embrace myriad economic and social changes. The transition has turned out to be vastly more complicated and extraordinary then first thought. The command economy and its highly inefficient administrative system were not only the style of distribution and governing but also a style of social interaction and thinking. This philosophy may be hidden as it is translated through the generations of policy makers however it continues to influence strategy. Moreover, the social importance of the old industrial enterprises as a major providers of social services including health care must not be overlooked (Gaddy and Ickes, 2002.) Substantial deterioration of economic and social infrastructures is common in these nations. When health care systems are compared, some members fared relatively better than others.

This research, is limited by the availability of data, assesses the efficiency of health care system in a sample of transition economy nations for the period of 1997-2001. The efficiency of each health care system, as compared with that of OECD countries, is measured by using DEA. In our analysis, life expectancy and infant mortality are used as outputs, while hospital beds, physicians, health care expenditure (all population adjusted figures) and percentage of children immunized for measles are incorporated as inputs.

During the period of 1997-2001, top performers, i.e., the most efficient systems, were OECD countries (their average inputs and outputs), Albania, and Armenia. The least efficient systems over an extensive period of time were Russia and Belarus, followed by Latvia and Romania. It is interesting to note that, in addition to the input and output variables, rates of alcohol and tobacco consumption as well as other socio-political factors also affected 
the efficiency rankings of transition countries. Higher efficiency in Albania and Armenia could be attributable to their policies to control the consumption of these products. In addition to the support from abroad (e.g., United States, Canada and other international organizations), both nations signed the international anti-tobacco treaty. These efforts reflected their determination to improve the public health over a period of economic and social instability. As a result, people in Albania and, to some extent, Armenia have been able to enjoy a relatively healthier life style as measured in terms of dietary habits and exercise.

Belarus' failure in terms of healthcare outcomes seems to be attributable to the failure in a comprehensive abandonment of the old command economy, mismanagement of the health care system, and the inability to stem the rise in cardiovascular and communicable diseases.

Russia's inadequacy reflects a parallel lack of restricting of old command economic policies by the government as well as the degradation of the environment and high rates of alcohol and tobacco use.

While decision makers in transition economies adopted policies one after another in their attempt to foster a transforming of the economy, few of the measure for changing social institutions and addressing health issues, such as alcohol consumption and tobacco use, have been fully implemented. Some of the intended effects have not been achieved because policy measures violate the "impermissibility constraint," those hidden styles of social interaction and thinking (Gaddy and Ickes, 2002). Incomplete implementation and the reversal policy can be the norms of transition in a nation such as Russia and Belarus. Cockerham (1997) is correct to point out that failures of transition economies to establish a strong health care system are due to the lack of sound policy, rising social stress, and an unhealthy lifestyle. Addressing these issues requires profound changes in government policies, health education, and public awareness.

\section{REFERENCES}

1. Anderson, G. F.; Reinhardt, U.; Hussey, P.; and Petrosyan, V., It's the Prices, Stupid: Why the United States is so Different from other Countries, Health Affairs, May/June 2003, Vol. 22, No. 3, 86.

2. Anell, A. and Willis, M., International Comparison of Health Care Systems Using Resource Profiles, Bulletin of the World Health Organization, June $28^{\text {th }}$, 2000, Vol. 78, No. 6, 770-778.

3. $\quad$ Berger, A. N.; Brockett, P.L.; Cooper, W.W.; and Pastor, J.T., New Approaches for Analyzing and Evaluating the Performance of Financial Institutions, European Journal of Operational Research, April 1997, Vol. 98, No. 2, 169-174.

4. Bhat, R., Methodology note: Data Envelopment Analysis (DEA), Journal of Health Management, JulyDecember 2001, Vol. 3, No.2, 309-328.

5. Bjorkgren, M.; Hakkinen, U.; and Linna, M., Measuring Efficiency of Long Term Care Units in Finland, Health Care Management Science, September 2001, Vol. 4, No. 3, 193.

6. $\quad$ Braithwaite, J.; Westbrook, M.; Hindle, D.; Ledema, R.; and Black, D., Does Restructuring Hospitals Result in Greater Efficiency?-an Empirical Test Using Diachronic Data, Health Services Management Research, February 2006, Vol. 19, No. 1, 1-13.

7. Brennan, A.; Sampson, F.; and Deverill, M., Can we Use Routine Data to Evaluate Organizational Change? Lessons from the Evaluation of Business Process Re-engineering in a UK Teaching Hospital, Health Services Management Research, November 2005, Vol. 18, No. 4, 265-277.

8. $\quad$ Brockett, P.; Chang, R.; Rousseau, J.; Semple, J.; and Yang, C., A Comparison of HMO Efficiencies as a Function of Provider Autonomy, Journal of Risk and Insurance, March 2004, Vol. 71, No. 1, 1-19.

9. Charnes, A.; Cooper, W.W.; and Rhodes, E., Measuring the Efficiency of Decision Making Units, European Journal of Operational Research, November 1978, Vol. 2, No. 6, 429-444.

10. Cherchye, L., Using Data Envelopment Analysis to Assess Macroeconomic Policy Performance, Applied Economics, February 2001, Vol. 33, No. 3, 407-416.

11. Cockerham, W.C.; Snead, M.C.; and Dewaal, D., Health Lifestyle in Russia and Socialist Heritage, Journal of Health and Social Behavior, March 2002, Vol.43, No.1, 14-36. 
12. Cockerham, W.C., The Social Determinants of the Decline of Life Expectancy in Russia and Eastern Europe: a Lifestyle Explanation, Journal of Health and Social Behavior, June 1997, Vol. 38, No.2, 117 131.

13. Cooper, W.W., Seiford, L.M. and Tone, K., Data Envelopment Analysis: a Comprehensive Text with Models, Applications, References and DEA-solver software, Boston: Kluwer Academic Publishers, 2000.

14. Dimelis, S. and Dimopoulou, M., Evaluating Productivity Growth Measures in EU, Economics of Planning: 2002, 2002, Vol.35, No. 2, 161-181.

15. European Observatory on Health Care Systems (2003), Health Care Systems in Transition, HiT summary: Albania, www.observatory.dk, 1-9.

16. Evans, D. B.; Tandon, A.; Murray, C. and Lauer, J., Comparative Efficiency of National Health Systems: Cross National Econometric Analysis, British Medical Journal, August 2001, Vol. 323, No.11, 307-310.

17. Farrell, M. J., The Measurement of Productive Efficiency, Journal of Royal Statistical Society, March $20^{\text {th }}$, 1957, Vol. 120, A, No. 3, 253-281.

18. Gaddy, G.G. and Ickes, B.W., Russia's Virtual Economy, Washington, D.C.: Brookings Institution Press, 2002.

19. Giokas, D., The Use of Goal Programming, Regression Analysis and Data Envelopment Analysis for Estimating Efficient Marginal Costs of Hospitals, Journal of Multicriteria Decision Analysis, Jul-Oct. 2002, Vol. 11, No. 4-5, 261-268.

20. Giuffrida, A., and Gravelle, H., Measuring Performance in Primary Care: Econometric Analysis and DEA, Applied Economics, 2001, Vol. 33, No. 2, 163-175.

21. Hofmarcher, M.M.; Paterson, I.; and Riedel, M., Measuring Hospital Efficiency in Austria - a DEA Approach, Health Care Management Science, February 2002, Vol. 5, No1, 7-14.

22. Hollingsworth, B.; Dawson, P.J.; and Maniakadis, N., Efficiency Measurement of Health Care: a Review of Non-parametric Methods and Applications, Health Care Management Science, 1999, Vol. 2, No. 3, 161 172 .

23. Key, B.; Reed, R.; and Sclar, D., First-order Economizing: Organizational Adaptation and the Elimination of Waste in the U.S. Pharmaceutical Industry, Journal of Managerial Issues, Winter 2005, Vol. 17, No. 4, 511-528.

24. Nyhan, R.C., and Cruise, P., Comparative Performance Assessment in Managed Care: Data Envelopment Analysis for Health Care Managers, Managed Care Quarterly, 2000, Vol. 8, No. 1, 18-27.

25. OECD, OECD Health Data, 2004, www.oecd.org/health/healthdata.

26. Seiford, L. M., Data Envelopment Analysis: The Evaluation of the State of the Art (1978-1985), The Journal of Productivity Analysis, 1996, Vol. 7, 99-137.

27. Smith, P., Model Misspecification in Data Envelopment Analysis, Annals of Operation Research, 1997, Vol.73, 233-252.

28. Thanassoulis, E., Introduction to the Theory and Application of Data Envelopment Analysis: a Foundation Text with Integrated Software, Boston: Kluwer Academic Publishers, 2001.

29. World Bank, Improving health and health care in Belarus, Belarus Health Policy Note, Report No. 24203, May 2002, http://lnweb18.worldbank.org/eca/belarus.nsf/6794d004fdefb34785256bfb00, pp. 1-17. 
NOTES 